\title{
Topiramate Use in Pediatric Patients
}

\author{
Tracy A. Glauser
}

\begin{abstract}
Topiramate (TPM), a new antiepileptic medication, is efficacious as adjunctive therapy in adults with partial onset seizures. Its efficacy as adjunctive therapy in children was evaluated in two randomized double-blind placebo-controlled trials involving childhood epileptic encephalopathy (the Lennox-Gastaut syndrome) and partial onset seizures. In these studies, topiramate adjunctive therapy resulted in a significant reduction in drop attacks (tonic or atonic seizures) in patients with the Lennox Gastaut syndrome and a significant reduction in partial onset seizures in children with refractory partial epilepsy. In both trials, TPM's efficacy improved as the dose escalated from the double-blind phase to the open-label portion. The minimally effective topiramate dose for adjunctive therapy in children with refractory epilepsy appears to be $6 \mathrm{mg} / \mathrm{kg} /$ day. Topiramate was well tolerated with mild or moderate side effects, predominantly related to the central nervous system. Practical tips are provided that may increase the chance that topiramate will be effective and well tolerated. The most important advice is a "start low, go slow" approach. An initial TPM dose of $0.5-1 \mathrm{mg} / \mathrm{kg} /$ day followed by weekly increments of $0.5-1$ $\mathrm{mg} / \mathrm{kg}$ is usually well tolerated. Based on these studies, topiramate appears to be an important addition to our pediatric AED armamentarium.
\end{abstract}

\begin{abstract}
RÉSUMÉ: Utilisation du topiramate en pédiatrie. Le topiramate (TPM), un nouveau médicament antiépileptique, est efficace comme traitement adjuvant chez les adultes qui ont des crises à début partiel. Son efficacité comme traitement adjuvant chez les enfants a été évalué lors de deux essais thérapeutiques randomisés, en double insu et contrôlés par placebo, chez des patients porteurs d'encéphalopathie épileptique de l'enfance (syndrome de Lennox-Gastaut) et des crises à début partiel. Dans ces études, le traitement adjuvant par le topiramate a entraîné une diminution significative des crises de salaam (crises toniques ou atoniques) chez les patients atteints du syndrome de Lennox-Gastaut et une diminution significative des crises à début partiel chez les enfants ayant une épilepsie partielle réfractaire au traitement. Dans les deux essais, l'efficacité du TPM a augmenté selon la dose en passant de la phase à double insu à la phase ouverte de l'étude. La plus petite dose efficace de topiramate pour le traitement adjuvant chez les enfants ayant une épilepsie réfractaire semble être $6 \mathrm{mg} / \mathrm{kg} / \mathrm{jour}$. Le topiramate a été bien toléré, avec des effets secondaires de légers à modérés, surtout au niveau du système nerveux central. Nous fournissons des suggestions pratiques pour augmenter les chances que le topiramate soit efficace et bien toléré. Le conseil le plus important est de commencer par une petite dose et d'augmenter lentement. Une dose initiale de 0.5 à $1 \mathrm{mg} / \mathrm{kg} / \mathrm{jour}$ suivie par des augmentations hebdomadaires de 0.5 à $1 \mathrm{mg} / \mathrm{kg}$ est généralement bien tolérée. Selon ces études, le topiramate semble être une addition importante à la pharmacopée antiépileptique pédiatrique.
\end{abstract}

Can. J. Neurol. Sci. 1998; 25: S8-S12

Topiramate (TPM) has demonstrated efficacy as adjunctive therapy in adults with partial onset seizures in six double-blind placebo-controlled clinical trials. ${ }^{1-6}$ These results, coupled with a broad spectrum of anticonvulsant action in animal and cellular studies, suggest TPM may be effective in childhood epilepsies. ${ }^{7}$ Two recently completed randomized double-blind placebo-controlled trials of topiramate adjunctive therapy in children shed light on this issue. The definitive publications on these two trials are not yet published; data are available from abstracts. ${ }^{8-14}$ These trials focused on two forms of refractory pediatric epilepsy: childhood epileptic encephalopathy (the Lennox-Gastaut syndrome) and partial onset seizures.

\section{Lennox-Gastaut Syndrome}

Childhood epileptic encephalopathy (the Lennox-Gastaut syndrome, LGS) is a devastating pediatric epilepsy syndrome consisting of multiple types of seizures (e.g., tonic, atonic, and absence seizures), mental retardation or regression, and an abnormal electroencephalogram (EEG) demonstrating general- ized slow spike and wave discharges $(1.5-2 \mathrm{~Hz})$ often associated with other multifocal EEG abnormalities. ${ }^{15-18}$ It constitutes $10 \%$ of all cases of epilepsy with onset in the first 5 years of life and $1-2 \%$ of all childhood epilepsies. ${ }^{19}$ The seizures in LGS patients often do not respond to conventional antiepileptic therapy. ${ }^{20.21}$ This group of patients is in need of new effective antiepileptic medications especially for the debilitating and potentially injurious tonic and atonic seizures.

A double-blind placebo-controlled multicenter trial of topiramate as adjunctive therapy in patients with Lennox-Gastaut syndrome has been recently completed and the results analyzed. ${ }^{8}$ The study's inclusion criteria were strict in an attempt to maximize the homogeneity of the participants. Children were poten-

From the Children's Comprehensive Epilepsy Program, Department of Neurology, Children's Hospital Medical Center, Cincinnati, Ohio. U.S.A.

Reprint requests to: Tracy A. Glauser, Director, Children's Comprehensive Epilepsy Program, Department of Neurology, OSB-5, Children's Hospital Medical Center, 3333 Burnet Avenue, Cincinnati, Ohio, U.S.A. 45229-3039 
tially eligible for the trial if they had multiple seizure types including documented drop attacks (either tonic or atonic seizures) and either an active history or past history of atypical absence seizures. Other seizure types were allowed but not required. The patient had to have a prior EEG demonstrating the classic "slow spike and wave" EEG pattern. Potential entrants had to be at least one year old, weigh $\geq 11.5$ kilograms, and have documented $\geq 60$ seizures in the month prior to enrolling in the baseline phase. Participants could be on one or two standard antiepileptic drugs. Exclusion criteria included the presence of a treatable or progressive neurologic disease, poor compliance, or a significant history of other medical conditions. ${ }^{8,12}$

After signing an Institutional Review Board approved Informed Consent, eligible patients underwent a 24 hour videoEEG telemetry. At each site, the principal investigator used this 24 hour video-EEG telemetry to confirm and classify seizure types and provide further education for the parents/guardians in order to maximize accurate identification of seizures. ${ }^{12}$ The 24 hour video-EEG was not used as an outcome variable but rather purely for parental/guardian education.

Following the 24 hour video-EEG telemetry, the patients entered into a 4 week baseline phase. During this phase, parent(s)/guardian(s) counted seizures and recorded their frequency in a diary. Concomitant antiepileptic drugs were kept constant. The patients were then randomized to either a placebo adjunctive therapy arm or a topiramate adjunctive therapy arm (Figure 1). Titration of the study drug occurred at one week intervals over a 3 week period: 1,3 , and $6 \mathrm{mg} / \mathrm{kg}$ /day (maximum dose $600 \mathrm{mg} /$ day).$^{8}$ Following the titration phase, an 8 week maintenance phase began during which both study drug and concomitant AEDs were held constant. ${ }^{8}$ At the end of this maintenance phase parent(s)/guardians(s) were asked to evaluate their child's current seizure severity compared to the child's baseline seizure severity. A seven point scale was used (marked- ly improved, moderately improved, minimally improved, no change, minimally worse, moderately worse, or markedly worse).

Subsequent to the completion of this double-blind phase of the trial, a 3 week double-blind conversion was performed; patients previously on the placebo adjunctive therapy arm were placed on topiramate (using the titration schedule listed above) while patients already on the topiramate adjunctive therapy arm were kept on the same dose. An open-label extension phase occurred after this double-blind conversion. ${ }^{10}$

Overall, 98 patients enrolled in this trial (50 randomized to placebo and 48 to topiramate). ${ }^{8}$ Ages ranged between 2 and 42 years old with a mean age of 11 years in both groups. ${ }^{8.10}$ The average TPM dose during the double-blind phase was 4.8 $\mathrm{mg} / \mathrm{kg} / \mathrm{day} .^{13}$ The median percent reduction from baseline for drop attacks in the topiramate group was $14.5 \%$ while the placebo group's median percent reduction was actually a $5 \%$ increase $(\mathrm{p}=0.04) .{ }^{13}$ At the end of the maintenance phase, 53\% of the parents/guardians in the TPM therapy arm felt that their child's seizure severity was either minimally, moderately or markedly improved compared to their baseline. This was significantly better than the $28 \%$ of parents/guardians in the placebo therapy arm who evaluated their child's seizure severity as either minimally, moderately or markedly improved $(\mathrm{p}=0.04){ }^{8}$

Topiramate appeared to be well tolerated in the double-blind portion of the trial. No patient withdrew for adverse events. ${ }^{8}$ Most of the side effects were rated as mild or moderate, were related to the central nervous system, ${ }^{8,13}$ and had a similar profile to that seen in TPM studies involving adults. ${ }^{7}$

The double-blind portion of this trial demonstrated that topiramate adjunctive therapy resulted in both a significant reduction in drop attacks and a significant improvement in parental global impression of seizure severity compared to placebo adjunctive therapy. Topiramate also appeared to be well tolerated. This double-blind portion of the trial provided rigorous scientific evidence of topiramate's efficacy against drop attacks in

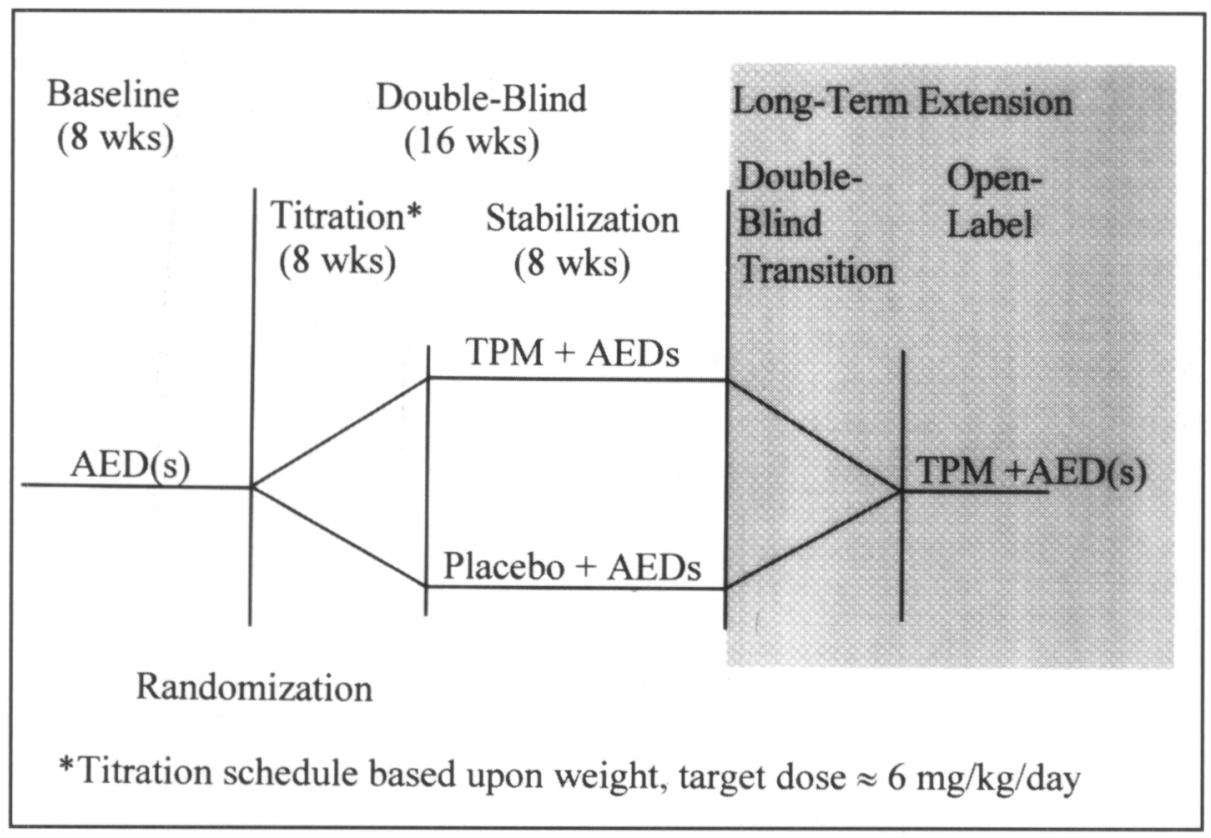

Figure 1: Study design of the randomized, double-blind, placebo-controlled trial of adjunctive topiramate therapy in patients with Lennox-Gastaut syndrome. $A E D(s)=$ Antiepileptic drug(s), TPM = topiramate, wks $=$ weeks. 
patients with Lennox-Gastaut syndrome.

The open-label portion of the trial sheds light on the magnitude of this effect. During the open-label portion of the trial, investigators were able to increase the topiramate dose to a maximum of $30 \mathrm{mg} / \mathrm{kg} /$ day and change concomitant medicines according to patient response. Thus, open-label studies such as the extension phase of this double-blind trial in Lennox-Gastaut syndrome can provide clinically relevant information about patient response and tolerability under study conditions more representative of clinical practice.

During the ongoing open-label portion of the LGS trial, 97 patients have taken TPM (mean dose of $11 \mathrm{mg} / \mathrm{kg} /$ day [range 1$29 \mathrm{mg} / \mathrm{kg} / \mathrm{day}$ ]) for a mean duration of 539 days (range 44-1225 days). ${ }^{10}$ Over half of these 97 patients $(58 \%$ ) have experienced a $\geq 50 \%$ reduction in drop attacks while $37 \%$ have had a $\geq 75 \%$ reduction in drop attacks. The overall total seizure frequency has been reduced by $\geq 50 \%$ in $43 \%$ of patients and by $\geq 75 \%$ in $23 \%$ of the patients. Most importantly, at the time of the most recent visit, $15 \%$ of the patients were free of drop attacks (2\% free of all seizures) for at least 6 months. ${ }^{10}$ There is no evidence, to date, that patients with LGS develop tolerance to TPM.

\section{Partial Onset Seizures}

A second randomized double-blind placebo-controlled pediatric trial of adjunctive topiramate therapy involved children with refractory partial onset seizures. In order to be eligible for the trial, children had to have 6 or more partial onset seizures during an 8 week baseline on 1-2 standard antiepileptic drugs. ${ }^{9}$

After the patient's parent(s)/guardian(s) signed an informed consent, an 8 week baseline period was performed where concomitant AEDs were held constant. Following this baseline phase, patients were randomized either to an topiramate adjunctive therapy arm or a placebo adjunctive therapy arm (Figure 2). Study drug was titrated over an 8 week period to a target dose based on weight $(125 \mathrm{mg} /$ day for $16-24.9 \mathrm{~kg} ; 175 \mathrm{mg} /$ day for
$25-33.9 \mathrm{~kg} ; 225 \mathrm{mg} / \mathrm{day}$ for $34-42.9 \mathrm{~kg}$; and $400 \mathrm{mg} / \mathrm{day}$ for $\geq$ $43 \mathrm{~kg}) .{ }^{9}$ Following titration, this assigned target dose or maximally tolerated dosage was maintained for 8 weeks. ${ }^{9}$ Throughout the entire study, each patient's seizure frequency was monitored by their parent(s)/guardian(s) and recorded in a diary. At the end of this maintenance phase parents were asked to evaluate their child's current seizure severity compared to the child's baseline seizure severity. A five point scale was used (markedly improved, moderately improved, minimally improved, no change, or worse).

Following the double-blind phase of the trial, an 8 week double-blind conversion occurred during which patients who had been on the placebo adjunctive therapy arm were administered steadily increasing doses of topiramate (according to the same schedule as mentioned above) while the patients who were on the topiramate adjunctive therapy arm were kept on their same dose. Following this double-blind conversion phase an openlabel extension phase of the trial was conducted. ${ }^{11}$

Overall, 86 patients participated in the trial $(n=45$ placebo adjunctive therapy, $n=41$ topiramate adjunctive therapy). Patients ranged in age from 2 to 17 years old. ${ }^{9}$ The study drug target dose was $6 \mathrm{mg} / \mathrm{kg} / \mathrm{day} .{ }^{9}$ The median percent reduction from baseline in partial onset seizures for the topiramate adjunctive therapy group was $33.1 \%$ compared with $10.5 \%$ for the placebo adjunctive therapy group $(\mathrm{p}=0.034) .{ }^{9}$ There was a difference in the $\geq 75 \%$ seizure reduction rates for the two groups (17\% of TPM vs. $2 \%$ of the placebo group, $\mathrm{p}=0.02$ ) but not in the $\geq 50 \%$ seizure reduction rates for the two groups $(39 \%$ of TPM vs. $20 \%$ of the placebo group, $p=0.08) .{ }^{14}$ Parents/guardians of children on the TPM adjunctive therapy arm noted a greater improvement in seizure severity compared with the evaluation by parents/guardians of children on the placebo adjunctive therapy $\operatorname{arm}(\mathrm{p}=0.03) .{ }^{14}$

Topiramate appeared to be well tolerated in the double-blind portion of the trial. During the double-blind phase, one patient

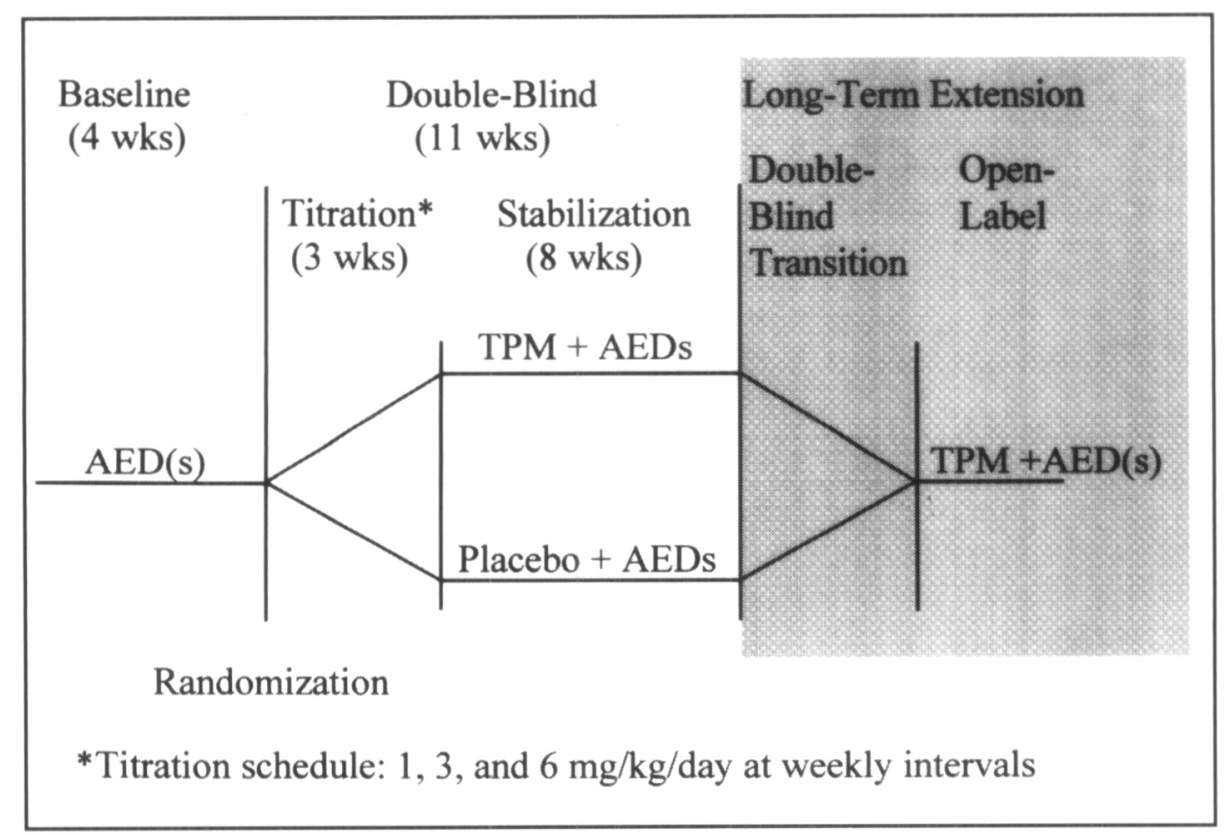

Figure 2: Study design of the randomized, double-blind, placebo-controlled trial of adjunctive topiramate therapy in patients with partial onset seizures. $A E D(s)=$ Antiepileptic drug $(s), T P M=$ topiramate, $w k s=$ weeks. 
on the placebo adjunctive therapy arm withdrew due to adverse events while no patients on the topiramate adjunctive therapy arm withdrew. ${ }^{14}$ Most of the side effects were rated as mild or moderate, related to the central nervous system, occurred with similar frequency in the two treatment arms, and had a similar profile to that seen in TPM studies involving adults. ${ }^{7,9,14}$

The double-blind portion of this trial demonstrated that topiramate adjunctive therapy resulted in both a significant reduction in partial onset seizures and a significant improvement in parental global impression of seizure severity compared to placebo adjunctive therapy. Topiramate also appeared to be well tolerated. This double-blind portion of the trial gives scientific rigorous evidence of topiramate's efficacy in pediatric partial onset seizures.

The open-label extension phase of this study can provide clinically relevant information about patient response and tolerability under study conditions more representative of clinical practice. During the open-label portion of the trial, investigators were able to increase the topiramate dose to a maximum of 30 $\mathrm{mg} / \mathrm{kg} /$ day and change concomitant medicines according to patient response. During the ongoing open-label portion of this trial, 83 patients have taken a mean TPM dose of $9 \mathrm{mg} / \mathrm{kg} / \mathrm{day}$ (range $4-22 \mathrm{mg} / \mathrm{kg} / \mathrm{day}$ ) for a mean duration of 440 days (range 96 - 923 days)..$^{1}$ Among these 83 patients, partial onset seizures were reduced $\geq 50 \%$ and $\geq 75 \%$ in $57 \%$ and $42 \%$ of patients respectively. At the time of the most recent visit, $14 \%$ of the patients had been seizure free for at least 6 months. "There is no evidence, to date, that children with partial onset seizures develop tolerance to TPM.

\section{Practical Tips}

These two trials demonstrate that topiramate is effective in children for drop attacks (tonic or atonic seizures) associated with the Lennox-Gastaut syndrome and partial onset seizures. A few tips (based on my experience as a principal investigator on both pediatric studies and with over 200 children on TPM in my clinical practice) may increase the chance that topiramate will be effective and well tolerated (Table 1).

The initial TPM dose and subsequent TPM titration rates are important. The topiramate titration schedules used in the studies were probably too rapid and therefore not optimal. At our institution, we use an initial dose of $0.5-1 \mathrm{mg} / \mathrm{kg} / \mathrm{day}$ followed by weekly increments of $0.5-1 \mathrm{mg} / \mathrm{kg}$. This titration can be slowed if adverse experiences occur but it can be accelerated if there is an urgent need for control of seizures. In our experience this "start low, go slow" titration regimen appears to be reasonably well tolerated.

Table 1: Practical tips.

"Start low, go slow"

Initial dose: $0.5-1.0 \mathrm{mg} / \mathrm{kg} / \mathrm{day}$

Titration rate: $0.5-1.0 \mathrm{mg} / \mathrm{kg} /$ week increments

Minimal effective dose appears to be $6 \mathrm{mg} / \mathrm{kg} / \mathrm{day}$

Always titrate to response (either seizure control without intolerable side effects or persistent seizures with intolerable side effects)

Alert parents to titration time ( $6-8$ weeks) to avoid undue frustration.
Based on the above two double blind trials, the minimally effective topiramate dose for adjunctive therapy in children with refractory epilepsy appears to be $6 \mathrm{mg} / \mathrm{kg} / \mathrm{day}$. As shown in Table 2, in the pediatric partial onset seizure trial, TPM's efficacy improved as the dose escalated from the double-blind phase to the open-label portion. In the double-blind phase of the pediatric partial onset seizure trial (TPM target dose $6 \mathrm{mg} / \mathrm{kg} / \mathrm{day}$ ), there was a difference between the two treatment arms in the $75 \%$ seizure reduction rate but not the $50 \%$ seizure reduction rate..$^{14}$ In the open-label portion (mean TPM dose $9 \mathrm{mg} / \mathrm{kg} /$ day) the $50 \%$ responder rates rose from $39 \%$ to $57 \% . .^{11}$ This implies that a recognizable number of patients had a dramatic response to TPM at $6 \mathrm{mg} / \mathrm{kg} / \mathrm{day}$ (or lower) but as a group higher TPM doses were more beneficial. A similar effect was observed in the LGS trial.

In our practice, some patients do respond to doses lower than $6 \mathrm{mg} / \mathrm{kg} /$ day while some need in excess of $15 \mathrm{mg} / \mathrm{kg} /$ day to achieve maximal effect. As with all antiepileptic medications, individual response to therapy is highly varied and antiepileptic medications need to be titrated to response (either seizure control without intolerable side effects or persistent seizures with intolerable side effects). Children who are taking 10-15 $\mathrm{mg} / \mathrm{kg} /$ day of topiramate and experiencing a noticeable reduction in seizure frequency without intolerable side effects should be pushed to higher doses. We have used doses as high as 50 $\mathrm{mg} / \mathrm{kg} /$ day (often in the setting of a concomitant enzyme inducing AED [e.g., carbamazepine]).

Using the above "start low, go slow" titration schedule and a minimally effective dose of $6 \mathrm{mg} / \mathrm{kg} /$ day, it follows that it will take approximately 6 - 8 weeks in order to begin to see a therapeutic effect. It is important to alert the patient's parent(s)/guardian(s) to this proposed time frame so that undue frustrations and expectations are avoided.

In our patient population there does appear to be a small subset of patients (approximately 1-3\%) who cannot tolerate even the smallest dose of topiramate. In these patients, significant central nervous system side effects (e.g., somnolence, fatigue, agitation) occur at extremely low doses. We discontinue the medication, wait 2 weeks and then offer a retrial. If again, at extremely low doses, side effects occur, then the patient is directed towards another medication. For this small group of patients, there have been no obvious characteristics that prospectively identify them as high risk for TPM side effects. However, the overwhelming majority of our patients tolerate the "start low, go slow" approach very well.

\section{CONCLUSION}

Topiramate is effective as adjunctive therapy against drop attacks (tonic or atonic seizures) associated with Lennox-Gastaut

Table 2: Increased topiramate efficacy as dose increases in pediatric partial onset seizures.

\begin{tabular}{lcc}
\hline Parameter & $\begin{array}{c}\text { Double-blind } \\
\text { phase }(\mathbf{n = 4 1})\end{array}$ & $\begin{array}{l}\text { Open-label phase } \\
(\mathbf{n}=\mathbf{8 3})\end{array}$ \\
\hline Mean dose $(\mathrm{mg} / \mathrm{kg} / \mathrm{day})$ & 6 & 9 \\
\hline$\geq 50 \%$ seizure reduction & $39 \%$ & $57 \%$ \\
\hline$\geq 75 \%$ seizure reduction & $17 \%$ & $42 \%$ \\
\hline
\end{tabular}


syndrome and partial onset seizures in children. Formal regulatory approval for topiramate use in children is pending in a number of countries. Even prior to actual regulatory approval, topiramate's use in children is growing in countries where it is approved for adults and available by prescription. This is not surprising and has been the case with other new antiepileptic medications (felbamate, lamotrigine, gabapentin).

Based on the two double-blind trials, the subsequent openlabel extension phases, and our clinical experience, we feel topiramate is an important addition to our pediatric AED armamentarium. Additional studies and worldwide clinical experience is needed to determine whether topiramate eventually will be considered a first line monotherapy medication for children with epilepsy.

\section{REFERENCES}

1. Faught E, Wilder BJ, Ramsay RE, et al. Topiramate placebo-controlled dose-ranging trial in refractory partial epilepsy using 200-, $400-$, and $600-\mathrm{mg}$ daily dosages. Topiramate YD Study Group. Neurology 1996; 46: 1684-1690.

2. Privitera M, Fincham R, Penry J, et al. Topiramate placebo-controlled dose-ranging trial in refractory partial epilepsy using 600-, $800-$, and 1,000-mg daily dosages. Topiramate YE Study Group. Neurology 1996; 46: 1678-1683.

3. Tassinari CA, Michelucci R, Chauvel $P$, et al. Double-blind, placebo-controlled trial of topiramate ( $600 \mathrm{mg}$ daily) for the treatment of refractory partial epilepsy. Epilepsia 1996; 37: 763-768.

4. Ben-Menachem E, Henriksen O, Dam M, et al. Double-blind, placebo-controlled trial of topiramate as add-on therapy in patients with refractory partial seizures. Epilepsia 1996; 37: 539-543.

5. Pledger G, Reife R, Lim P. Topiramate: intent-to-treat and other analyses. Epilepsia 1996; 37: 72 (Abstr, Suppl 4).

6. Reife RA, Pledger G, Lim P. Topiramate: pooled analysis of six placebo-controlled trials. Epilepsia 1996; 37 : 74 (Abstr, Suppl 4).

7. Glauser TA. Topiramate. Semin in Pediatr Neurol 1997; 4: 34-42.
8. Glauser TA, Sachdeo RC, Ritter FJ, Reife R, Lim P. Topiramate in Lennox-Gastaut syndrome: a double blind trial. Neurology 1997; 48: 1729 (Abstr).

9. Elterman R, Glauser TA, Ritter FJ, Reife R, Wu SC. Efficacy and safety of topiramate in partial seizures in children. Neurology 1997; 48: 1729 (Abstr).

10. Ritter FJ, Glauser TA, Sachdeo RC, Wu SC. Topiramate as longterm therapy in Lennox-Gastaut syndrome. Neurology 1998; 50 (4): A312 (Abstr, Suppl 4).

11. Glauser TA, Elterman R, Wyllie E. Long-term topiramate therapy in children with partial-onset seizures. Neurology 1998; 50(4): A99-A 100 (Abstr, Suppl 4).

12. Glauser TA, Sachdeo RC, Ritter FJ, Reife R, Lim P. A double blind trial of topiramate in Lennox-Gastaut syndrome (LGS). Epilepsia 1997; 38: 131 (Abstr, Suppl 3).

13. Glauser TA, Sachdeo RC, Ritter FJ, Reife R, Lim P. Topiramate as adjunctive therapy in Lennox-Gastaut syndrome. Epilepsia 1997; 38: 207 (Abstr, Suppl 8).

14. Elterman R, Glauser TA, Ritter FJ, Reife R, Wu SC. Topiramate as adjunctive therapy in pediatric patients with partial-onset seizures. Epilepsia 1997; 38: 98 (Abstr, Suppl 8).

15. Dulac O, N'Guyen T. The Lennox-Gastaut syndrome. Epilepsia 1993; 34: Suppl 7: S7-S17.

16. Beaumanoir A, Dravet C. The Lennox-Gastaut syndrome. In: Roger J, Bureau M, Dravet C, Dreifuss FE, Perret A, Wolf P, eds. Epileptic Syndromes in Infancy, Childhood and Adolescence (2nd edition), John Libbey \& Company, Ltd., 1992: 115-132.

17. Kotagal P. Multifocal independent Spike Syndrome: relationship to hypsarrhythmia and the slow spike-wave (Lennox-Gastaut) syndrome. Clin Electroencephalogr 1995; 26: 23-29.

18. Commission on Classification and Terminology of the International League Against Epilepsy. Proposal for Revised Classification of Epilepsies and Epileptic Syndromes. Epilepsia 1989; 30: 389-399.

19. Hauser WA. The prevalence and incidence of convulsive disorders in children. Epilepsia 1994; 35: Suppl 2: S1-S6.

20. Glauser TA. Pediatric epilepsy syndromes. Curr Opin Pediatrics 1995; 7: 640-649.

21. Donaldson JA, Glauser TA, Olberding LS. Lamotrigine adjunctive therapy in childhood epileptic encephalopathy. Epilepsia 1997; 38: $68-73$. 